\title{
Morpho-Physiological Traits Linked to High Temperature Stress Tolerance in Tomato (S. lycopersicum L.)
}

\author{
Muhammed Alsamir ${ }^{1,2 *}$, Nabil M. Ahmad ${ }^{1}$, Tariq Mahmood ${ }^{1}$, Richard Trethowan ${ }^{1}$ \\ ${ }^{1}$ Plant Breeding Institute, Faculty of Agriculture and Environment, University of Sydney, Cobbitty, Australia. \\ ${ }^{2}$ The Date Palm Research Centre, University of Basrah, Basrah, Iraq \\ Email: *alsamir.hameed@sydney.edu.au, malsamir@hotmail.com
}

How to cite this paper: Alsamir, M., Ahmad, N.M., Mahmood, T. and Trethowan, R. (2017) Morpho-Physiological Traits Linked to High Temperature Stress Tolerance in Tomato (S. lycopersicum L.). American Journal of Plant Sciences, 8, 2681-2694. https://doi.org/10.4236/ajps.2017.811180

Received: August 5, 2017

Accepted: October 16, 2017

Published: October 19, 2017

Copyright $\odot 2017$ by authors and Scientific Research Publishing Inc. This work is licensed under the Creative Commons Attribution International License (CC BY 4.0).

http://creativecommons.org/licenses/by/4.0/

\begin{abstract}
The identification of heat tolerance traits that express across environments is key to the successful development of high temperature tolerant tomatoes. A replicated experiment of 145 tomato genotypes was established at two temperature regimes in two planting seasons using hydroponics in a poly greenhouse to assess high temperature tolerance. Electrolyte leakage, number of inflorescences, number of flowers and fruits, fresh fruit weight and fresh and dry plant weight were measured and genotype and temperature treatment differences were observed for all traits. Planting season impacted all traits except electrolyte leakage and number of flowers. High temperature reduced number of fruits by $88.8 \%$, flower fruit set ratio by $77.2 \%$ and fresh fruit weight by $79.3 \%$. In contrast, traits little impacted by temperature included number of flowers per inflorescence (1.3\%) and plant dry weight (11.1\%). The correlation between plant dry weight under both high and optimal temperature was significant $\left(R^{2}=0.82\right)$. To assess the effectiveness of plant dry weight and flower-fruit set ratio for selection under heat stress two subsets of genotypes (A and B) comprising ten and six genotypes respectively, were subsequently selected on the basis of their dry weight loss and flower-fruit set ratio under high temperature. Organic metabolite analyses of set A and B respectively, showed a significant change (\%) in citric acid (77.4 and 15.4), L-proline (117.8 and 40.2), aminobutyric acid (68.6 and 11.8), fructose (24.9 and 21.3), malic acid (50.3 and 42.7), myo-inositol (55.1 and 6.1), pentaerythitol (54.1 and 39.0 ) and sucrose (34.7 and 25.8). The change (\%) in all metabolites was greater in heat tolerant genotypes with the exception of fructose and sucrose where sensitive genotypes produced a higher variation. The change in sucrose in tolerant genotypes was variable in subset $A$ and more uniform in subset $B$. Flower-fruit set ratio was found as a reliable trait for discriminating between
\end{abstract}


heat tolerant and sensitive genotypes and the sucrose levels in plant tissues provided confirmation of the heat stress response.

\section{Keywords}

Tomato Traits, High Temperature Stress, Hydroponic Media, Heat Stress Response

\section{Introduction}

Tomato ( $S$. lycopersicum) belongs to the family solanaceae and was domesticated in the Andean region of South America and Mexico [1]. Tomato was introduced to Europe in the $16^{\text {th }}$ century and later spread throughout the Mediterranean region [2] [3] [4]. Thousands of tomato cultivars have subsequently been developed through breeding and selection [5].

Climate change has increased the incidence of heat stress in many crop production environments globally [6] [7] [8]. Several traits have been implicated in heat stress tolerance in tomato including membrane thermo stability (MTS), floral characteristics, cone splitting, pollen viability, fruit set and fruit yield [8]-[13]. High temperature at the reproductive stage of development causes significant flower drop [14] resulting in decreased fruit set and yield [15]. Heat stress adversely affects Style elongation and pollen germination and limits pollen tube growth. Exposure to temperatures above $25^{\circ} \mathrm{C}$ significantly reduces fruit number, fruit weight and seed number per fruit [16]. Heat shock at extremely high temperature $\left(\geq 45^{\circ} \mathrm{C}\right)$ can lead to programmed cell death (PCD), release of cytochrome $c$ and activation of caspase-like enzymes [17]. Plant reproductive organs are clearly more sensitive to heat stress than vegetative parts [18] [19].

High temperature increases root heat stress and affects nutritional quality because of a disturbed root nutrient relationship [20]. High-temperature stress thus limits root growth and reduces the shoot system and subsequent fruit production by limiting water supply, nutrients and the production of hormones that influence sink-source associations between roots and shoots [19] [21]. Heat stress is a significant cause of reduced tomato yield in Mediterranean and tropical countries [22].

Tomatoes experience heat stress at temperature $\geq 35^{\circ} \mathrm{C}$ when most genotypes suffer physiological and biochemical damage. High temperature has been observed to increase transpiration [23] [24] [25] and reduce photosynthesis [26] [27] by altering membrane fluidity and disrupting the overall balance of metabolic processes.

It is argued that the breeding, screening and selection of tomato genotypes is more effective at the vegetative and fruit bearing stages [15]. Pedigree selection and backcross hybridization have been used extensively to improve yield and fruit quality traits under heat stress conditions [28]. The inheritance of heat to- 
lerance traits in tomato is reported to be low (5\% - 19\%) because of the influence of environment on trait expression [29] [30] [31].

Organic metabolites like glycine, betaine, proline and mannitol are known to play a role in maintaining membrane integrity and scavenging the reactive oxygen species [21] [32] [33]. However, more heat tolerant genotypes are able to maintain pollen starch and sugar levels under high temperature [34] [35]. Heat stress also reduces carbohydrate accumulation in pollen grains and the ATP level of stigmatic tissue [36]. Reduction in the sink- and source-strength can lead to reduced fruit set and other yield related parameters in tomato. Reproductive development fails when sugar metabolism and proline transport are disrupted under heat stress [37]. Nevertheless, exogenous application of organic metabolites can mitigate the effects of heat stress [21] [32].

A consistent genotype response to both optimal and heat stressed conditions is important for yield stability. This study evaluated the impact of heat stress on the vegetative and reproductive development of diverse tomato genotypes with the aim of identifying traits of high heritability that could be used to improve the high temperature tolerance of tomato.

\section{Materials and Methods}

\subsection{Plant Materials}

One hundred and forty six tomato accessions collected from around the world including one accession each of the wild species $S$. pimpinellifolium, $S$. pennellii and $S$. chilense were evaluated. Seeds of 44 accessions were obtained from the Tomato Genetic Resource Centre (UC Davis, USA), 43 accessions from the World Vegetable Centre (AVRDC, Taiwan), 47 from Vegetable Research Institute, Faisalabad, Pakistan and 10 from the Diggers Club, Australia. All experiments were established from cuttings of source materials to avoid errors due to genetic variability.

\subsection{Weather Data}

Temperature, relative humidity and photosynthetically active radiation (PAR) in the green house in both temperature treatments were recorded using a CR200X Data Logger (CAMPBELL SCIENTIFIC, INC., Australia) as shown in Figure 1.

\subsection{Phenotyping}

The set of 144 tomato accessions was phenotyped during summer 2014-2015 in optimal and heat stress conditions. The experiment comprised two planting dates; mid-season and late season. The materials were grown in a hydroponic greenhouse in cocopeat bags at The University of Sydney's Plant Breeding Institute (Latitude: -34.02, Longitude: 150.67, Altitude: $87 \mathrm{~m}$ ). Each cocopeat bag contained one plant and each genotype was replicated twice. The plants were fertigated with a nutrient solution formulated for commercial tomato production. Two temperature treatments were created in two separate sections of the poly 

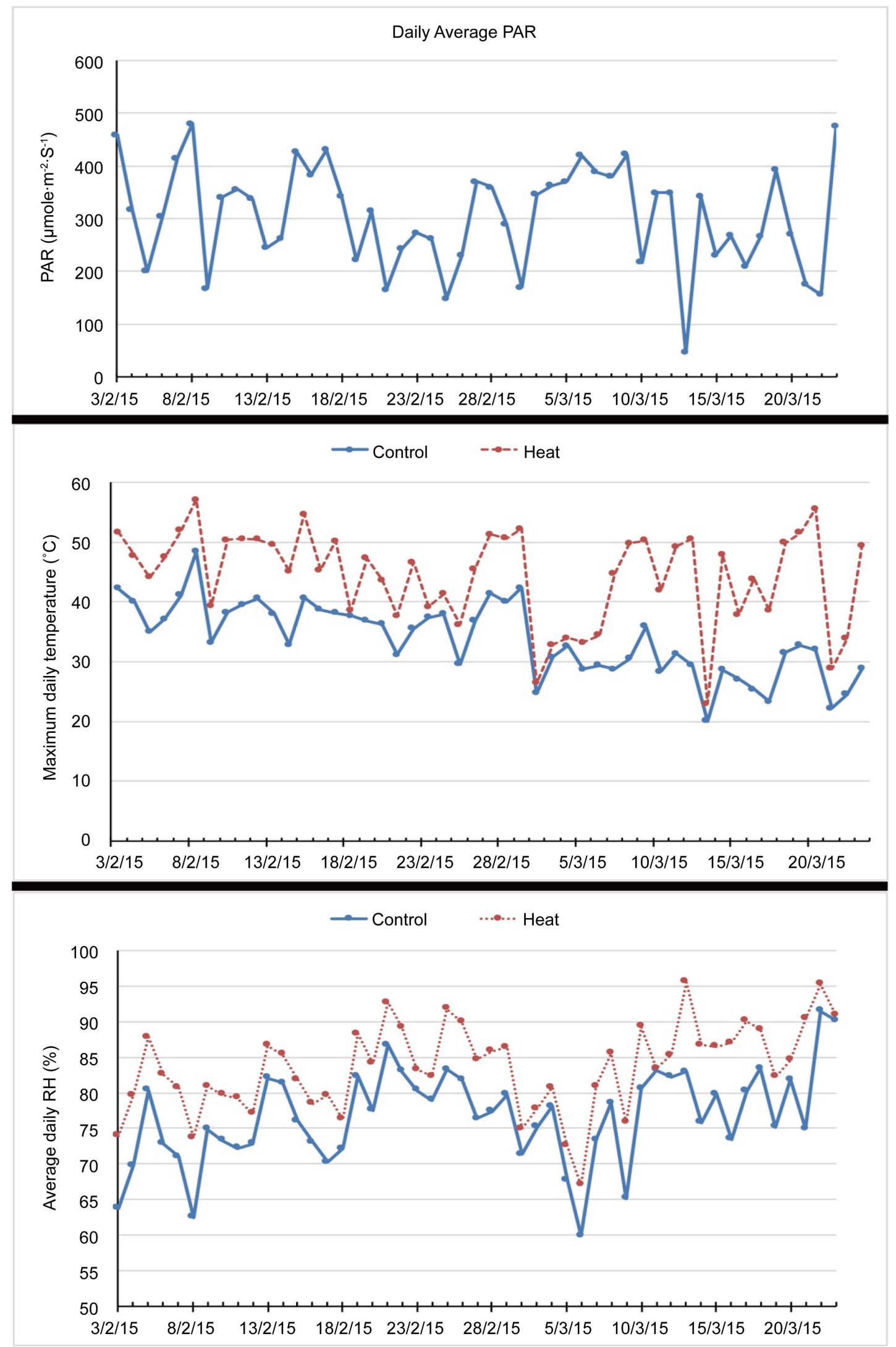

Figure 1. Temperature, relative humidity and photosynthetically active radiation (PAR) recorded inside the tunnel house on a daily basis. 
green house. Management protocols in both sections were identical with the exception of the temperature treatment. The high temperature section accumulated heat from the sun and temperatures at midday exceeded $50^{\circ} \mathrm{C}$ on some days (measured at c. $2 \mathrm{~m}$ height and c. $50 \mathrm{~cm}$ above the canopy). The temperature differential in each section was maintained using controlled ventilation. On hot days, the ventilation was more closely monitored to avoid excessive heat damage. The temperature, relative humidity and photosynthetically active radiation (PAR) were recorded (Figure 1) using a CR200X data logger (Campbell Scientific Australia, Townsville, Qld, Australia). Seven traits were assessed including: number of inflorescences per plant (IPP), number of flowers per inflorescence (FPI), number of fruits per plant (FPP), fruit fresh weight (FFW), plant fresh weight (PFW), plant dry weight (PDW) and electrolyte leakage (EL). Electrolyte leakage was recorded at the start of flowering following the protocol described by [38].

The EL score presented the mean of four independent measurements taken on different plants in each treatment. Electrolyte leakage is considered an indirect measure of heat stress tolerance; the lower the EL value higher the tolerance. Six leaf segments of uniform maturity from each plant were cut into discs and washed three times with de-ionized water to eliminate external surface residues. Discs were placed in $50 \mathrm{ml}$ Greiner centrifuge tubes (Sigma Aldrich, Australia) with $20 \mathrm{ml}$ of de-ionized water and maintained on a shaker at $80 \mathrm{rpm}$ for 20 hours. The conductivity of the solution was subsequently read with a conductivity meter (Edge, Hanna Instruments Inc. HI11310 single ceramic, double junction, refillable $\mathrm{pH}$ electrode with temperature sensor). The samples were then autoclaved at $121^{\circ} \mathrm{C}$ and 15 psi pressure for $15 \mathrm{~min}$ to kill the tissue and burst all cells and conductivity recorded again. The percentage of electrolytes originally diffused was calculated as follows: Electrolyte $(\%)=\mathrm{C} 1 / \mathrm{C} 2 \times 100$, where $\mathrm{C} 1$ and $\mathrm{C} 2$ are the conductivities of the solution before and after autoclaving, respectively.

Leaf tissue samples were preserved for the subsequent organic metabolite analyses. A subset of ten genotypes (subset-A) was selected on the basis of dry weight loss (\%) for further analysis. Five genotypes with the smallest dry weight loss and another five with the highest dry weight loss were included in the subset. Another subset of six genotypes (subset-B) was selected on the basis of flower-fruit set ratio. Three genotypes with highest fruit set (\%) and another three with lowest fruit set comprised this subset. Organic metabolites including citric acid, L-proline, aminobutyric acid, fructose, malic acid, myo-inositol, pentaerythitol and sucrose were assessed on both subsets using the protocols outlined below.

\subsection{Methanol/Chloroform/Water (MCW) Extraction Method}

$40 \mathrm{mg}$ of freeze-dried tissue was weighed into a $2 \mathrm{ml}$ Eppendorf tube (screw cap) and $1 \mathrm{ml} \mathrm{MCW} \mathrm{(12:5:3)} \mathrm{was} \mathrm{added} \mathrm{and} \mathrm{the} \mathrm{mixture} \mathrm{incubated} \mathrm{at} 75^{\circ} \mathrm{C}$ for 30 
min, agitating from time to time. Water was used as the internal standard $(0.4 \mathrm{~g}$ of both penta-erythritol and xylitol dissolved in $100 \mathrm{ml} \mathrm{MQ}$ water). The mixture was centrifuged and $800 \mu \mathrm{l}$ of supernatant was decanted into a clean Eppendorf tube. $500 \mu \mathrm{l}$ of MQ water and $200 \mu \mathrm{l}$ chloroform were added and mixed thoroughly with a vortex mixer, centrifuged and let stand for $10 \mathrm{~min} .700 \mu \mathrm{l}$ of the alcohol/aqueous phase (top) was removed and placed in a clean, round bottom Eppendorf tube already filled with $400 \mu \mathrm{l}$ of dry mixed bed resin. The tube was shaken for $2 \mathrm{hrs}$, then centrifuged and $400 \mu \mathrm{l}$ decanted into a clean Eppendorf tube. Samples were frozen and subsamples for derivatisation were placed into GC vials and dried [39].

\subsection{Gas Chromatography Analysis}

Following extraction, the samples were analysed immediately using gas chromatography coupled with a triple quadruple mass spectrometer (GC-QQQ, Agilent Technologies, Santa Clara CA) as per [39]. Fifty microliters of the extract were dried and re-suspended in $400 \mu \mathrm{L}$ anhydrous pyridine to which $50 \mu \mathrm{L}$ of trimethylchlorosilane (TMCS)/bis-trimethylsilyl-trifluoroacetamide mix (1:10, Sigma Aldrich, St Louis, MO) was added. Samples were incubated for $1 \mathrm{~h}$ at $75^{\circ} \mathrm{C}$ and analysed by gas chromatography within $12 \mathrm{~h}$. Separation of soluble carbohydrates and sugar alcohols was performed using an Agilent 7890A gas chromatograph (Agilent Technologies, Santa Clara, CA, USA) with a HP5 column (0.25 $\mathrm{mm}$ i.d., $30 \mathrm{~m}, 0.25 \mathrm{~mm}$ film thickness; Agilent Technologies, Santa Clara, CA, USA). Split injection was made at $300^{\circ} \mathrm{C}$ with an initial oven temperature program of $60^{\circ} \mathrm{C}$ for $2 \mathrm{~min}$, ramping up to $300^{\circ} \mathrm{C}$ at a rate of $10^{\circ} \mathrm{C} \cdot \mathrm{min}^{-1}$ and maintained for $10 \mathrm{~min}$. Column flow rate was maintained at $1.5 \mathrm{~mL} \cdot \mathrm{min}^{-1}$. Peak integration was determined using Agilent Mass Hunter Workstation software (Agilent Technologies, Santa Clara, CA, USA).

\subsection{Statistical Analyses}

The data were normalized using standard deviation and analysis of variance conducted using a fixed effect model (GenStat v 18.0 statistical software package). Differences were considered significant at $\mathrm{P}<0.05$. Scatter plots were constructed using Microsoft Excel 2010.

\section{Results}

Genotype and heat treatment effects were significant for electrolyte leakage, numbers of inflorescences, numbers of flowers, number of fruit, fruit set, fresh fruit weight, fresh plant weight and dry plant weight (Table 1). Season effects were also significant with the exception of electrolyte leakage and numbers of flowers. All two-way interactions were significant with the exception of treatment $\mathrm{x}$ season for numbers of flowers. Similarly, the three-way interactions were significant with the exception of electrolyte leakage. Those traits most impacted by heat stress included numbers of fruit, fruit weight and fruit set. Traits little 
Table 1. Analysis of variance for various traits from the evaluation of 145 genotypes in two temperature treatments across two seasons.

\begin{tabular}{|c|c|c|c|c|c|c|c|c|c|}
\hline TRAIT & SOV & $\mathrm{DF}$ & MS & Prob & TRAIT & SOV & DF & MS & Prob \\
\hline \multirow{7}{*}{ EL (\%) } & Genotype & 145 & 301.27 & $<0.001$ & \multirow{7}{*}{ Fruit Set (\%) } & Genotype & 142 & 376 & $<0.001$ \\
\hline & Treat & 1 & 13011 & $<0.001$ & & Treat & 1 & 228000 & $<0.001$ \\
\hline & Season & 1 & 20.87 & 0.209 & & Season & 1 & 2370 & $<0.001$ \\
\hline & Genotype.Treat & 144 & 202.81 & $<0.001$ & & Genotype.Treat & 91 & 268 & $<0.001$ \\
\hline & Genotype.Season & 144 & 26.49 & $<0.001$ & & Genotype.Season & 142 & 7.35 & $<0.001$ \\
\hline & Treat.Season & 1 & 15.54 & $<0.001$ & & Treat.Season & 1 & 2370 & $<0.001$ \\
\hline & Geno.Treat.Seas & 144 & 37.76 & 0.278 & & Geno.Treat.Seas & 11 & 94.9 & $<0.001$ \\
\hline \multirow{7}{*}{$\begin{array}{c}\text { No. } \\
\text { Inflorescence }\end{array}$} & Genotype & 145 & 675.96 & $<0.001$ & \multirow{7}{*}{$\begin{array}{l}\text { Fresh Fruit } \\
\text { Wt }(\mathrm{g})\end{array}$} & Genotype & 142 & 1870000 & $<0.001$ \\
\hline & Treat & 1 & 10615 & $<0.001$ & & Treat & 1 & 89400000 & $<0.001$ \\
\hline & Season & 1 & 353.24 & $<0.001$ & & Season & 1 & 1400000 & $<0.001$ \\
\hline & Genotype.Treat & 144 & 65.53 & $<0.001$ & & Genotype.Treat & 91 & 1090000 & $<0.001$ \\
\hline & Genotype.Season & 144 & 18.71 & $<0.001$ & & Genotype.Season & 142 & 1690 & $<0.001$ \\
\hline & Treat.Season & 1 & 353.24 & $<0.001$ & & Treat.Season & 1 & 1400000 & $<0.001$ \\
\hline & Geno.Treat.Seas & 140 & 19.25 & $<0.001$ & & Geno.Treat.Seas & 11 & 21800 & $<0.001$ \\
\hline \multirow{7}{*}{ No. flower } & Genotype & 145 & 10.2 & $<0.001$ & \multirow{7}{*}{$\begin{array}{c}\text { Fresh Pl Wt } \\
\text { (g) }\end{array}$} & Genotype & 145 & 6830000 & $<0.001$ \\
\hline & Treat & 1 & 1.23 & $<0.001$ & & Treat & 1 & 16800000 & $<0.001$ \\
\hline & Season & 1 & 0 & 0.651 & & Seasoniroment & 1 & 814000 & $<0.001$ \\
\hline & Genotype.Treat & 143 & 0.2 & $<0.001$ & & Genotype.Treat & 145 & 210000 & $<0.001$ \\
\hline & Genotype.Season & 144 & 0.01 & $<0.001$ & & Genotype.Season & 144 & 98900 & 0.025 \\
\hline & Treat.Season & 1 & 0 & 0.65 & & Treat.Season & 1 & 5700000 & $<0.001$ \\
\hline & Geno.Treat.Seas & 140 & 0.01 & $<0.001$ & & Geno.Treat.Seas & 144 & 104000 & $<0.001$ \\
\hline \multirow{7}{*}{ No. Fruit } & Genotype & 142 & 2060 & $<0.001$ & \multirow{7}{*}{$\begin{array}{l}\text { Dry Pl Wt } \\
\quad(\mathrm{g})\end{array}$} & Genotype & 145 & 19880 & $<0.001$ \\
\hline & Treat & 1 & 354000 & $<0.001$ & & Treat & 1 & 81641 & $<0.001$ \\
\hline & Season & 1 & 3270 & $<0.001$ & & Season & 1 & 7225 & $<0.001$ \\
\hline & Genotype.Treat & 91 & 2060 & $<0.001$ & & Genotype.Treat & 145 & 1047.3 & $<0.001$ \\
\hline & Genotype.Season & 142 & 8.12 & $<0.001$ & & Genotype.Season & 144 & 730.5 & $<0.001$ \\
\hline & Treat.Season & 1 & 3270 & $<0.001$ & & Treat.Season & 1 & 42507 & $<0.001$ \\
\hline & Geno.Treat.Seas & 11 & 105 & $<0.001$ & & Geno.Treat.Seas & 144 & 727 & $<0.001$ \\
\hline
\end{tabular}

impacted by stress included numbers of flowers and plant dry weight (Figure 2).

Fruit weight and plant dry weight were correlated across temperature regimes (Figure 3).

The percentage change in plant dry weight (subset-A) and fruit set (subset-B) is presented in Figure 4. The cultivar Amish Paste was little affected whereas LA 4273 suffered the greatest dry weight loss in subset-A. Long Keeper was relatively 


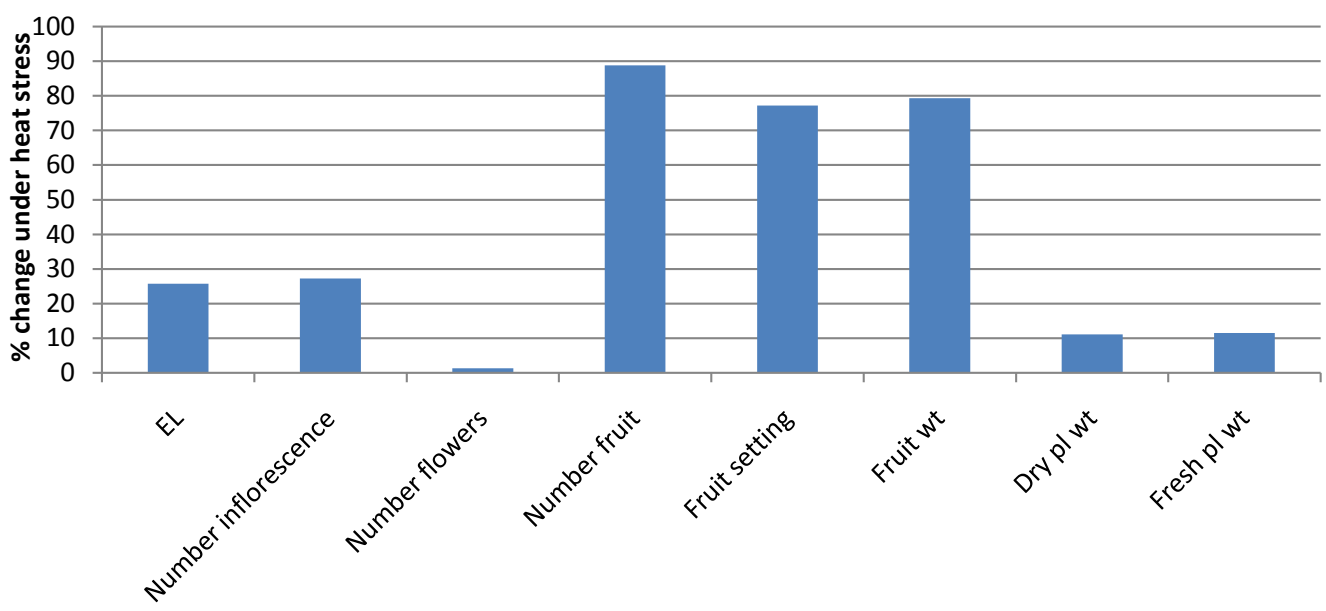

Figure 2. Mean change in various plant traits following high temperature stress.
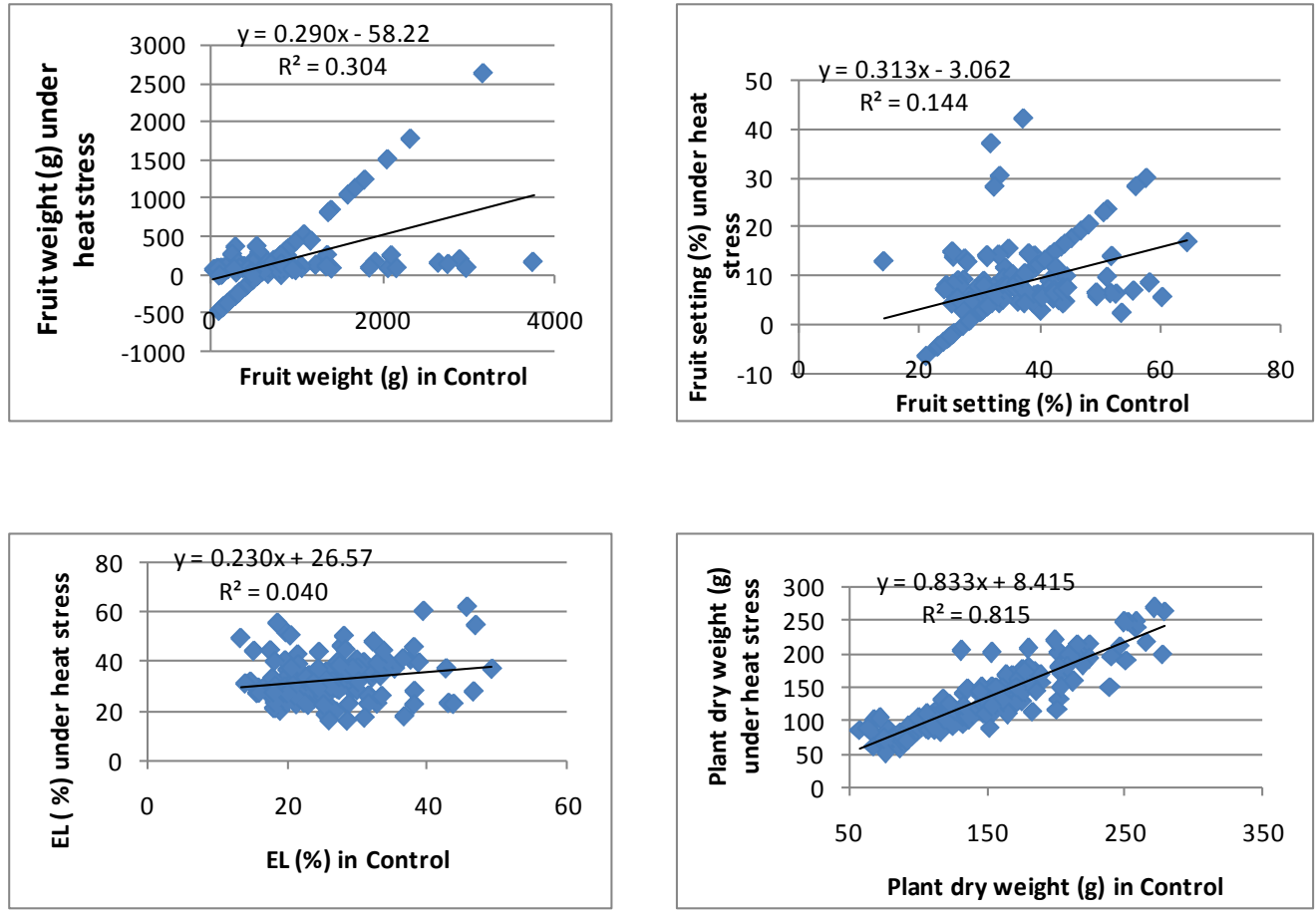

Figure 3. Relationship between fruit weight, fruit set, plant dry weight and electrolyte leakage (EL) under control and heat stress conditions.

unaffected by heat stress in subset-B and the dry weight loss was greatest in LA 4283.

L-proline and aminobutyric acid both increased significantly in tolerant genotypes under heat stress in subset-A (Figure 5) and the smallest change was observed for sucrose and fructose. In contrast, sensitive genotypes produced more citric acid and sucrose in response to stress. In subset-B, the greatest change in tolerant genotypes under heat stress was observed for malic acid, pentaerythitol and L-proline and the smallest change noted for sucrose and fructose. In contrast, the sensitive genotypes were again higher in sucrose and fructose. 

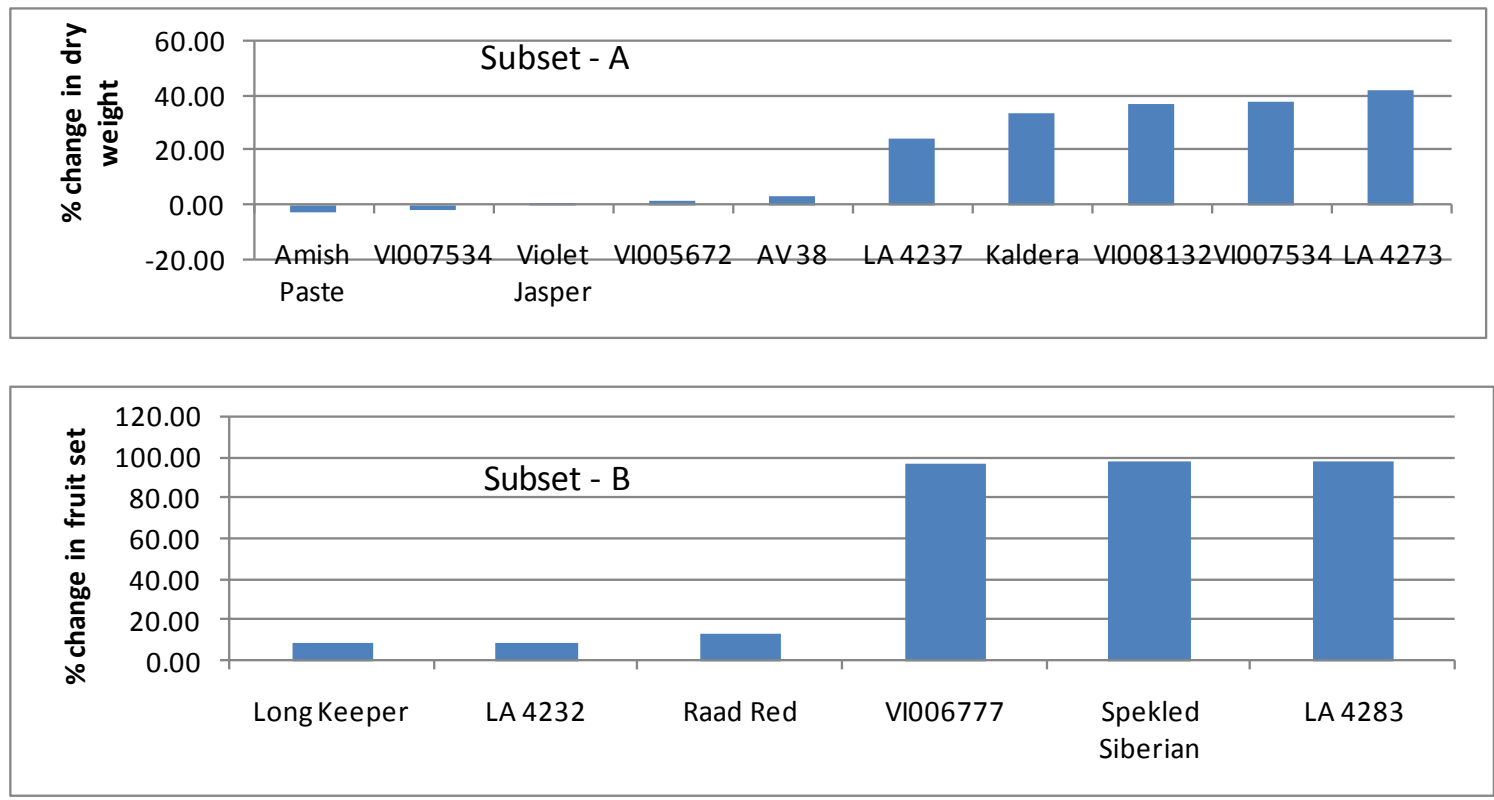

Figure 4. Percentage change in dry weight of ten genotypes (subset-A) selected on the basis of dry weight loss and fruit set in six genotypes (subset-B) selected on the basis of change in fruit set under high temperature stress.

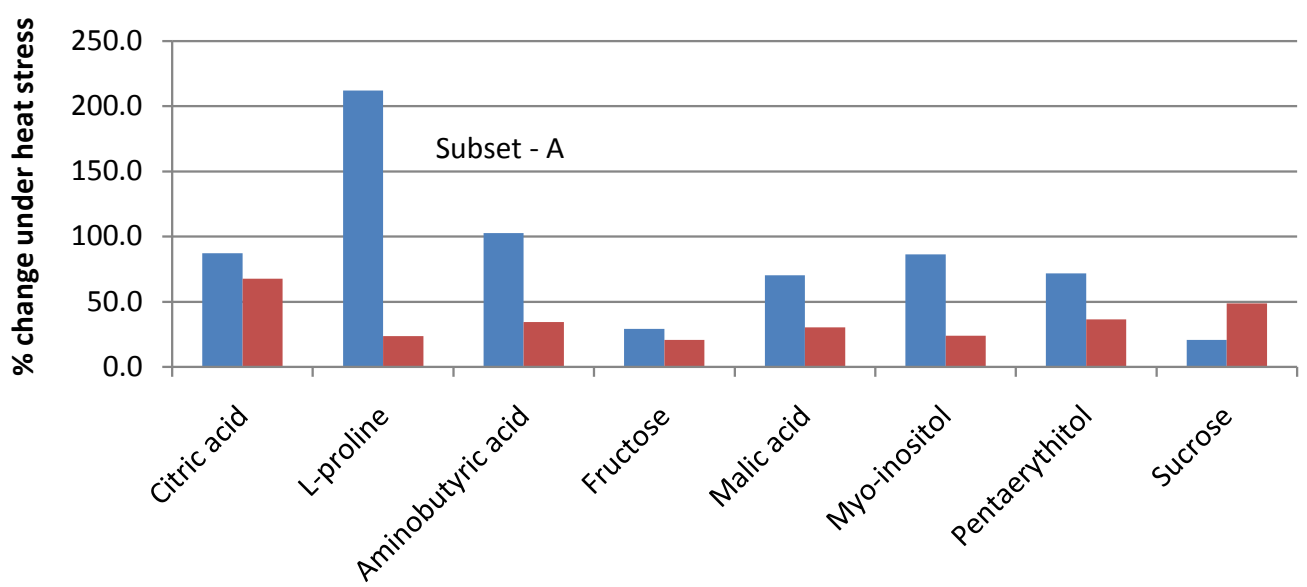

- Tolerant

Sensitive

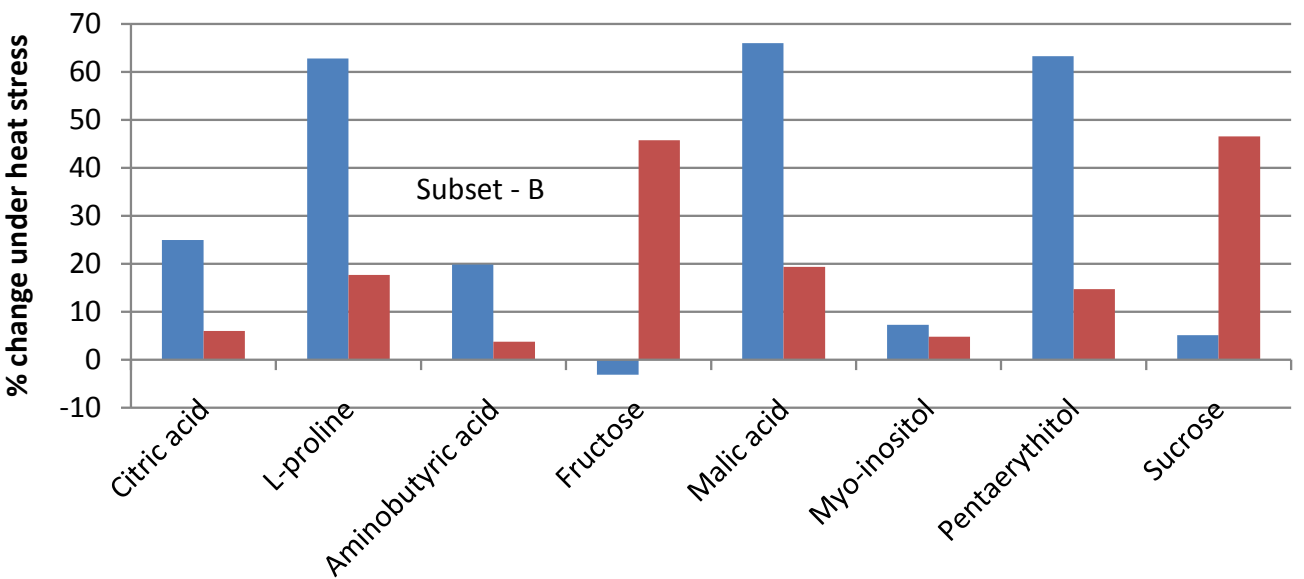

- Tolerant

Sensitive

Figure 5. Percentage change in metabolite content in heat tolerant and sensitive genotypes under heat stress in subsets $\mathrm{A}$ and $\mathrm{B}$. 
The association between change in dry weight and L-proline was negative and significantly high in both the sub sets (Figure 6). A high and positive correlation was observed between change in dry weight and sucrose in both the subsets. However, the change in sucrose was very low in subset-B compared to subset-A.

\section{Discussion}

The significant genotypic variability for all the high-temperature response traits assessed suggests that tomato heat tolerance can be significantly improved. However, pyramiding these traits is dependent upon the assumptions of additive variance and a lack of compensatory mechanisms that limit expression of higher levels of heat tolerance.

While heat stress response varied by trait, the fruit related traits were most reduced limited by heat stress (Figure 2). Number of fruit per plant was severely impacted yet the number of flowers and plant biomass showed little change. It appears that fruit set was the limiting factor under stress and this supports earlier reports [6] [30] [40]. Plant dry weight was little impacted between temperature regimes (Figure 3 ) indicating that the vegetative tissues were relatively little affected by elevated temperature. The plant biomass was strongly genetically controlled as different genotypes produced significantly different biomass.

The percentage change in various metabolites observed in tolerant genotypes
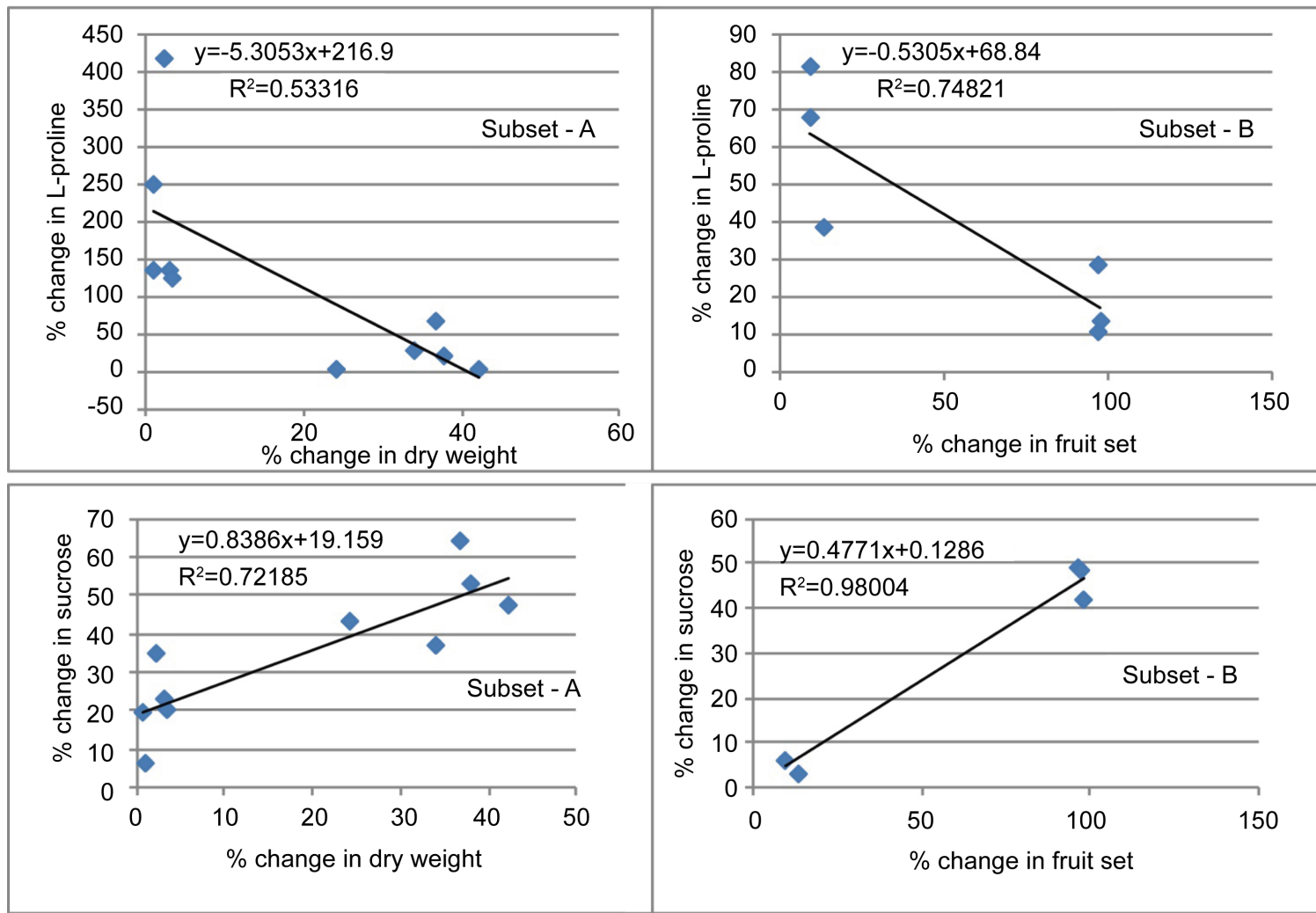

Figure 6. Relationship between change in dry weight and sucrose in heat tolerant and sensitive genotypes in ten genotypes selected on the basis of dry weight loss (A) and six genotypes selected on the basis of drop in fruit setting (B). 
(with the exception of sucrose) suggests that these compounds have a protective role in plant tissues under stress [41] (Figure 5). L-proline in particular was linked to enhanced stress response and may be responsible for maintenance of biomass under heat stress [41]. Nevertheless, the stress response is likely to be complex as malic acid, pentaerythitol, and L-proline were all up-regulated in subset- $\mathrm{B}$ and this probably provided more stable fruit setting in tolerant genotypes under heat stress [41].

While L-proline was greater in tolerant genotypes under stress, the percentage dry weight loss and fruit set did not necessarily correspond to the level of L-proline increase. These observations are similar to those of [42]. Clearly, mechanisms other than L-proline were also important in determining the dry weight and fruit setting under heat stress conditions [32] [33].

The observed change in sucrose was lower in the tolerant genotypes than sensitive genotypes indicating that this change in dry weight is to some extent dependent upon sucrose level; however sucrose was not the sole cause of this change [43]. Fruit set in both tolerant and sensitive genotypes was generally dependent upon the stability of sucrose levels in tissues (Figure 6). While flower set was little affected by heat stress, the flower-fruit set ratio was a useful trait for the selection of genotypes tolerant to heat stress. Those genotypes that were able to convert a higher proportion of flowers into fruit showed higher levels of tolerance and this supports earlier findings [21] [34] [35]. Reproductive heat stress tolerance is therefore vital and this was most likely linked to decreased pollen viability in sensitive genotypes. This study found that maintenance of higher levels of sucrose in plant tissues was an indication of higher flower-fruit set ratio under heat stress conditions [16] [18].

\section{Conclusions}

For effective selection under heat stress conditions plant breeding programs need to identify traits linked to heat stress tolerance. The current study concluded that under heat stress conditions:

o dry weight loss and flower-fruit set ratio are useful traits to categorise genotypes.

o various organic metabolites are up/down regulated and the extent of change may depend on the tolerance/sensitivity of the genotype.

0 the capacity to maintain sucrose level in the plant tissues indicates the capacity of a genotype to maintain higher flower-fruit set ratio.

\section{Acknowledgements}

Authors thankfully acknowledge the help and contributions made by the students and staff of the Plant Breeding Institute, The University of Sydney. Authors also gratefully acknowledge the cooperation extended by TGRC at UC Davis for providing the germplasm, and ACIAR vegetables project HORT/2012/002 for supporting the heat stress research in tomatoes. 


\section{References}

[1] Bai, Y. and Lindhout, P. (2007) Domestication and Breeding of Tomatoes: What Have We Gained and What Can We Gain in the Future. Annals of Botany, 100, 1085-1094. https://doi.org/10.1093/aob/mcm150

[2] Esquinas Alcazar, J.T. (1981) Genetic Resources of Tomatoes and Wild Relatives. International Board for Plant Genetic Resources, Rome.

[3] Pék, Z. and Helyes, L. (2004) The Effect of Daily Temperature on Truss Flowering Rate of Tomato. Journal of the Science of Food and Agriculture, 84, 1671-1674. https://doi.org/10.1002/jsfa.1858

[4] Rodríguez, G.R., Muños, S., Anderson, C., Sim, S.C., Michel, A., Causse, M., Gardener, B.B.M., Francis, D. and van der Knaap, E. (2011) Distribution of SUN, OVATE, LC, and FAS in the Tomato Germplasm and the Relationship to Fruit Shape Diversity. Plant Physiology, 156, 275-285.

https://doi.org/10.1104/pp.110.167577

[5] Acquaah, G. (2009) Principles of Plant Genetics and Breeding. John Wiley \& Sons, Hoboken.

[6] Bita, C.E. and Gerats, T. (2013) Plant Tolerance to High Temperature in a Changing Environment: Scientific Fundamentals and Production of Heat Stress-Tolerant Crops. Frontiers in Plant Science, 4. https://doi.org/10.3389/fpls.2013.00273

[7] Hedhly, A., Hormaza, J. and Herrero, M. (2009) Flower Emasculation Accelerates Ovule Degeneration and Reduces Fruit Set in Sweet Cherry. Scientia Horticulturae, 119, 455-457. https://doi.org/10.1016/j.scienta.2008.08.020

[8] Sato, S., Peet, M. and Thomas, J. (2000) Physiological Factors Limit Fruit Set of Tomato (Lycopersicon esculentum Mill.) under Chronic, Mild Heat Stress. Plant, Cell \& Environment, 23, 719-726. https://doi.org/10.1046/j.1365-3040.2000.00589.x

[9] Golam, F., Prodhan, Z.H., Nezhadahmadi, A. and Rahman, M. (2012) Heat Tolerance in Tomato. Life Science Journal, 9, 1936-1950.

[10] Saeed, A., Hayat, K., Khan, A.A. and Iqbal, S. (2007) Heat Tolerance Studies in Tomato (Lycopersicon esculentum Mill.). International Journal of Agriculture and Biology, 9, 649-652.

[11] Abdul-Baki, A.A. and Stommel, J.R. (1995) Pollen Viability and Fruit Set of Tomato Genotypes under Optimum and High-Temperature Regimes. HortScience, 30, 115-117.

[12] Giorno, F., Wolters-Arts, M., Mariani, C. and Rieu, I. (2013) Ensuring Reproduction at High Temperatures: The Heat Stress Response during Anther and Pollen Development. Plants, 2, 489-506. https://doi.org/10.3390/plants2030489

[13] Keller, M., Hu, Y., Mesihovic, A., Fragkostefanakis, S., Schleiff, E. and Simm, S. (2016) Alternative Splicing in Tomato Pollen in Response to Heat Stress. DNA Research, 24, 205-217. https://doi.org/10.1093/dnares/dsw051

[14] Hanna, H., Hernandez, T. and Koonce, K. (1982) Combining Ability for Fruit-Set, Flower Drop, and Underdeveloped Ovaries in Some Heat-Tolerant Tomatoes. HortScience, 17, 760-761.

[15] Berry, S. and Rafique, U.M. (1988) Effect of High Temperature on Fruit Set in Tomato Cultivars and Selected Germplasm. HortScience, 23, 606-608.

[16] Peet, M., Sato, S. and Gardner, R. (1998) Comparing Heat Stress Effects on MaleFertile and Male-Sterile Tomatoes. Plant, Cell \& Environment, 21, 225-231. https://doi.org/10.1046/j.1365-3040.1998.00281.x 
[17] Xia, Y., Liu, Y., Wan, J., Wang, M., Rocchi, P., Qu, F., Iovanna, J.L. and Peng, L. (2009) Novel Triazole Ribonucleoside Down-Regulates Heat Shock Protein 27 and Induces Potent Anticancer Activity on Drug-Resistant Pancreatic Cancer. Journal of Medicinal Chemistry, 52, 6083-6096. https://doi.org/10.1021/jm900960v

[18] Li, Z., Palmer, W.M., Martin, A.P., Wang, R., Rainsford, F., Jin, Y., Patrick, J.W., Yang, Y. and Ruan, Y.L. ( 2011) High Invertase Activity in Tomato Reproductive Organs Correlates with Enhanced Sucrose Import into, and Heat Tolerance of, Young Fruit. Journal of Experimental Botany, 63, 1155-1166. https://doi.org/10.1093/jxb/err329

[19] Zinn, K.E., Tunc-Ozdemir, M. and Harper, J.F. (2010) Temperature Stress and Plant Sexual Reproduction: Uncovering the Weakest Links. Journal of Experimental Botany, 61, 1959-1968. https://doi.org/10.1093/jxb/erq053

[20] Giri, A., Heckathorn, S., Mishra, S. and Krause, C. (2017) Heat Stress Decreases Levels of Nutrient-Uptake and -Assimilation Proteins in Tomato Roots. Plants, 6, 6. https://doi.org/10.3390/plants6010006

[21] Wahid, A., Gelani, S., Ashraf, M. and Foolad, M.R. (2007) Heat Tolerance in Plants: An Overview. Environmental and Experimental Botany, 61, 199-223.

[22] Mansour, A., Ismail, H., Ramadan, M.F. and Gyulai, G. (2009) Variations in Tomato (Lycopersicon esculentum) Cultivars Grown under Heat Stress. Journal für Verbraucherschutz und Lebensmittelsicherheit, 4, 118-127. https://doi.org/10.1007/s00003-009-0474-5

[23] Li, L., Jia, L., Qing, G. and Jin-Xing, C. (2015) Effects of Day and Night Temperature Difference on Growth, Development, Yield and Fruit Quality of Tomatoes. The Journal of Applied Ecology, 26.

[24] Rivero, R.M., Ruiz, J.M., Garcia, P.C., Lopez-Lefebre, L.R., Sánchez, E. and Romero, L. (2001) Resistance to Cold and Heat Stress: Accumulation of Phenolic Compounds in Tomato and Watermelon Plants. Plant Science, 160, 315-321.

[25] Khanal, B. (2012) Effect of Day and Night Temperature on Pollen Characteristics, Fruit Quality and Storability of Tomato. Norwegian University of Life Sciences.

[26] Islam, M. (2011) Effect of Temperature on Photosynthesis, Yield Attributes and Yield of Tomato Genotypes. International Journal of Experimental Agriculture, 2, 8-11.

[27] Salvucci, M.E. and Crafts-Brandner, S.J. (2004) Relationship between the Heat Tolerance of Photosynthesis and the Thermal Stability of Rubisco activase in Plants from Contrasting Thermal Environments. Plant Physiology, 134, 1460-1470. https://doi.org/10.1104/pp.103.038323

[28] Ibrahim, E.A. (2016) Seed Priming to Alleviate Salinity Stress in Germinating Seeds. Journal of Plant Physiology, 192, 38-46.

[29] Abdul-Baki, A.A. (1991) Tolerance of Tomato Cultivars and Selected Germplasm to Heat Stress. Journal of the American Society for Horticultural Science, 116, 1113-1116.

[30] Ibrahim, E.S.Z. (2016a) Tomato Breeding for Heat Stress Conditions. European Journal of Academic Essays, 3, 87-93.

[31] Villareal, R.M. and Juliano, B.O. (1978) Properties of Glutelin from Mature and Developing Rice Grain. Phytochemistry, 17, 177-182.

[32] Chen, T.H. and Murata, N. (2008) Glycinebetaine: An Effective Protectant against Abiotic Stress in Plants. Trends in Plant Science, 13, 499-505.

[33] Szabados, L. and Savouré, A. (2010) Proline: A Multifunctional Amino Acid. Trends in Plant Science, 15, 89-97. 
[34] Pressman, E., Peet, M.M. and Pharr, D.M. (2002) The Effect of Heat Stress on Tomato Pollen Characteristics Is Associated with Changes in Carbohydrate Concentration in the Developing Anthers. Annals of Botany, 90, 631-636. https://doi.org/10.1093/aob/mcf240

[35] Firon, N., Shaked, R., Peet, M., Pharr, D., Zamski, E., Rosenfeld, K., Althan, L. and Pressman, E. (2006) Pollen Grains of Heat Tolerant Tomato Cultivars Retain Higher Carbohydrate Concentration under Heat Stress Conditions. Scientia Horticulturae, 109, 212-217.

[36] Jain, M., Prasad, P.V., Boote, K.J., Hartwell, A.L. and Chourey, P.S. (2007) Effects of Season-Long High Temperature Growth Conditions on Sugar-to-Starch Metabolism in Developing Microspores of Grain Sorghum (Sorghum Bicolor L. Moench). Planta, 227, 67-79. https://doi.org/10.1007/s00425-007-0595-y

[37] Sato, S., Kamiyama, M., Iwata, T., Makita, N., Furukawa, H. and Ikeda, H. ( 2006) Moderate Increase of Mean Daily Temperature Adversely Affects Fruit Set of $L y$ copersicon esculentum by Disrupting Specific Physiological Processes in Male Reproductive Development. Annals of Botany, 97, 731-738.

[38] Lafuente, M.T., Belver, A., Guye, M.G. and Saltveit, M.E. (1991) Effect of Temperature Conditioning on Chilling Injury of Cucumber Cotyledons Possible Role of Abscisic Acid and Heat Shock Proteins. Plant Physiology, 95, 443-449.

https://doi.org/10.1104/pp.95.2.443

[39] Merchant, A., Richter, A., Popp, M. and Adams, M. (2006) Targeted Metabolite Profiling Provides a Functional Link among Eucalypt Taxonomy, Physiology and Evolution. Phytochemistry, 67, 402-408.

[40] Abdelmageed, A.H.A. and Gruda, N. (2009) Influence of Grafting on Growth, Development and Some Physiological Parameters of Tomatoes under Controlled Heat Stress Conditions. European Journal of Horticultural Science, 74, 16-20.

[41] Alsamir, M., Ahmad, N.M., Mahmood, T. and Trethowan, R. (2017) Impact of heat Stress on Fusarium Wilt ( $F$. solani) Incidence in Cultivated Tomato and Related Species. Australian Journal of Crop Science, 11, 997-1004. https://doi.org/10.21475/ajcs.17.11.08.pne500

[42] Kinnersley, A.M. and Turano, F.J. (2000) Gamma Aminobutyric Acid (GABA) and Plant Responses to Stress. Critical Reviews in Plant Sciences, 19, 479-509.

[43] Murchie, E.H., Sarrobert, C., Contard, P., Betsche, T., Foyer, C.H. and Galtier, N. (1999) Overexpression of Sucrose-Phosphate Synthase in Tomato Plants Grown with $\mathrm{CO}_{2}$ Enrichment Leads to Decreased Foliar Carbohydrate Accumulation Relative to Untransformed Controls. Plant Physiology and Biochemistry, 37, 251-260. 